\title{
La cerámica de Manises y Paterna S.XIV-XV:
} els socarrats 
Antes de la aparición del documento escrito, la cerámica ya nos habla del hombre, puesto que a través de ella podemos conocer muchas de sus costumbres, hábitos de vida y creencias. El hombre siempre ha amado la belleza, y un reflejo de este amor podemos encontrarlo, desde sus inicios, en formas y decoraciones muy primitivas, pero en numerosas ocasiones, cargadas de simbolismo.

Se ha optado por la utilización del método bibliográfico consistente en la búsqueda y recopilación de información contenida en distintas fuentes, sobre la cerámica en general, analizando y extrayendo la que interesa para realizar el presente trabajo.

Este trabajo se basa en una revisión historiográfica e iconográfica sobre la cerámica de Manises y Paterna durante los siglos XIV al XVI, profundizando en la creación de los tableros conocidos como socarrats.

Paraules clau: Socarrats, Manises, Paterna, Iconografía, Historia del Arte

\section{Introducción}

Las cerámicas de los talleres de Manises y Paterna son herencia de la época musulmana, surgiendo para satisfacer las necesidades de estas poblaciones y de otras próximas a ellas. La producción estaba basada principalmente en utensilios de vajilla para uso cotidiano y piezas destinadas a la construcción.

Tanto en Manises como en Paterna, la cerámica se distinguió por su gran desarrollo, que en un principio era común a las dos localidades, siendo la mayoría de los alfareros musulmanes.

A lo largo de de los siglos XIV al XVI, la creación cerámica de Manises y Paterna alcanzó un importante aumento, en cuanto al número de piezas obradas, a su calidad y, con una variedad en sus formas y decoración, que propició su exportación, sobre todo a través del Mediterráneo.

Fue en Paterna en donde se elaboraron la mayoría, pero no la totalidad de los socarrats, ya que, en menor número, también se realizaron en Manises.

Els socarrats tomaron los motivos iconográficos de la cerámica utilitaria y de la heráldica, adecuándolos a su formato.

\section{Objetivos}

El objetivo de este trabajo es hacer un estudio comparativo de los motivos iconográficos representados, en una muestra compuesta por piezas de la cerámica de Manises y Paterna, pertenecientes a cerámica vidriada en verde-manganeso y a cerámica de reflejo metálico, con otra de 
piezas de socarrats, todas ellas producidas durante estos siglos, y de cómo estos han sido transferidos desde el soporte de vajilla al de piezas arquitectónicas.

Se incluye dentro de esta transferencia de la iconografía, la que se produce entre la heráldica medieval valenciana trazada sobre soporte cerámico vidriado y los socarrats; cuales se transfieren y como varían para adaptarse a los nuevos soportes.

Los típicos socarrats de Paterna han pasado prácticamente desapercibidos para el mundo del arte, como en general ha ocurrido con la mayor parte de las obras realizadas en cerámica. El motivo de haber elegido como tema els socarrats es el dar a conocer tanto los temas que en ellos se representan,-como su ejecución

\section{Resultados}

\subsection{La cerámica de Manises y Paterna s. XIV-XVI}

Manises y Paterna son dos localidades con larga tradición alfarera, iniciada mucho antes de la reconquista del Reino de Valencia por el Rey Jaime I de Aragón en el año 1237. Un año después de esta, Jaime I ordenó la redacción notarial del "Llibre del Repartiment", en el que consignaba la alquería de Manises y la de Paterna al noble aragonés Artal de Luna. A partir de este momento la producción cerámica, de estas dos poblaciones, se desarrolla paralelamente, lo que hace que en muchas ocasiones sea imposible distinguir la procedencia de las piezas. Tanto de los hornos de Manises como de los de Paterna saldrán piezas decoradas en verde y morado, como en azul o en reflejo metálico.

En el año 1309, Pere Boil adquiere Manises potenciando la cerámica que allí se produce, interesado por beneficiarse del cobro de diezmos a los alfareros.

Los principales hornos se encontraban en manos de mudéjares, ya que el propio Jaime I decretó la prohibición de utilizar los hornos árabes a judíos y cristianos, y será a partir del siglo XV cuando aparecen los alfareros cristianos. Según Villanueva (2006: 258), en las dos últimas centurias de la época medieval, Guillermo de Osma censó más de cien nombres de alfareros musulmanes y cristianos en las poblaciones de Manises y Paterna, que, reagrupados con los maestros de obra, formaron un gremio distinto a principios del siglo XVI. Su producción, a la vez que decorativa y utilitaria, se orientaba a la fabricación de vajilla o de revestimientos murales y de embaldosados.

La producción cerámica es muy variada, existiendo una especialización en los centros alfareros según el tipo de piezas cerámicas que realizaban: tarros de boticarios y morteros, jarras de arcilla cocida, azulejos para revestimiento, vajilla, etc. La mayoría de la cerámica llamada fina, decorada a mano con pincel sin modelo previo, y objetos muy refinados de gran belleza, tenían como destinatarios, mayoritariamente, a la aristocracia y a la nobleza (COLL, 2009: 110). 
En el repertorio ornamental, de estas cerámicas, se mezclan influencias musulmanas y cristianas, con motivos que van desde los puramente geométricos, a los vegetales, animales, representaciones humanas, epigráficos, y arquitectónicos.

Durante los siglos XIV y XVI, la producción cerámica de Manises y Paterna alcanzó un importante aumento, en cuanto al número de piezas obradas, a su calidad y, con una variedad en sus formas y decoración, que propició su exportación, debido a la demanda de muchos países mediterráneos, llegando a Portugal, Francia y especialmente a Italia, en donde como ejemplo encontramos la Capilla de los Justiciano de Santa Elena en Venecia (1450-70), en la que aparecen epigráficos con su nombre, además de temas vegetales con decoración de hojas de helecho estilizadas, como las que se pintan en los reversos de la loza dorada (Coll, 2009: 107). No solo son los países del Mediterráneo los receptores de importantes piezas de loza y azulejos, sino que estas llegan al otro lado del Atlántico (Villanueva, 2006: 259).

Este intercambio se produjo, tanto a nivel de materiales y productos como de alfareros, llegando incluso a Venecia, en donde el senado hizo una excepción en su arancel de aduanas a favor de la cerámica de Manises, puesto que las demás tenían prohibida su entrada (Villanueva, 2006: 260).

Así pues, la época de máximo esplendor de la cerámica de Manises y Paterna se inicia durante el siglo XIV y se extenderá hasta el siglo XVI, no obstante, el siglo XV es conocido como el siglo de oro, con un aumento de las exportaciones por países del Mediterráneo.

Los socarrats corresponden, en su gran mayoría al siglo XIV, siendo su principal centro productor Paterna.

Dentro de la cerámica de Manises y Paterna de los siglos XIV al XVI, encontramos piezas decoradas en verde y manganeso, siendo esta combinación mas típica de Paterna, otras exclusivamente en azul. La producción en azul con reflejo metálico, se da esencialmente en Manises, donde también se realizan piezas en las que se utiliza el blanco como base, y cuya decoración es exclusivamente a base de reflejo metálico.

Entre los temas más representados encontramos: los andromorfos, en los que las figuras femeninas tienen un claro predominio sobre las masculinas. Otros motivos como los zoomorfos, con gran variedad de aves, peces, ciervos, conejos o liebres, caballos, toros o leones, temas vegetales, arquitectónicos, epigráficos, profilácticos y heráldicos entre otros (González, 1944).

\subsection{Els socarrats}

La palabra socarrat ha sido utilizada para denominar a un tipo de piezas cerámicas, decoradas con motivos realizados con gran sencillez, que han formado parte de la construcción de las techumbres de edificios durante los siglos XIV-XVI.

La fabricación de socarrats ha sido típica de Paterna, aunque también podemos encontrarlos en la producción de Manises pero en menor número (SOLER, 1988: 237). 
Se trata de una loseta de barro cocida a la que se le aplicaba una capa de cal, decorando sobre esta con colores rojo oscuro y negro, en crudo. Carecía de segunda cocción, y se colocaban entre las vigas de madera de los techos y en los aleros.

\subsection{Técnica de fabricación dels Socarrats}

Lo primero que necesitaba el ceramista era una buena arcilla. Los antiguos alfareros tenían por costumbre extraer la arcilla de un lugar cercano a los hornos, también esto ocurría en la zona de Manises y Paterna. La elaboración de las piezas cerámicas se realizaba de forma artesanal, tanto la creación de la losa rectangular de barro como su decoración.

Era primordial realizar una adecuada preparación de la pasta, antes de pasar a la ejecución de cualquier tipo de pieza cerámica, con un buen amasado de la pella hasta eliminar cualquier burbuja interior que pudiese tener, ya que estas podían provocar roturas durante la cocción. Este amasado también servía para homogenizar el barro, dándole la misma consistencia a toda la pella. La pella es el volumen de barro que se toma para efectuar un mismo amasado.

Una vez terminado el amasado de la pella, se pasaba a la realización de la plancha, que podía ser mediante molde o con utilización de listones, dándole el mismo grosor en todas sus partes, unos tres centímetros. La pieza era cortada con la longitud deseada para el socarrat.

Independientemente del proceso elegido para la fabricación de la plancha, siempre se tenía que tener especial cuidado en la contracción de la pasta, pues con el secado y la cocción las dimensiones de esta menguan. Por lo tanto, era importante e imprescindible asegurarse a la hora de realizar el cálculo de dicha contracción para que, una vez terminada la pieza, no resultase demasiado pequeña, de manera que se acoplará perfectamente al espacio para el que estaba destinada. Un mal cálculo de esta contracción, supondría el invalidar la pieza, teniendo que ser desechada.

Sin esperar a que la plancha secase completamente, sino que cuando se encontraba en estado, de lo que en cerámica se conoce como dureza de cuero, se decoraba, cubriendo primeramente el fondo de toda la plancha con una capa de engobe de tierra blanca muy calcárea.

Sobre esta capa blanca se realizaban los distintos motivos decorativos, aplicando para ello la combinación de los óxidos en negro y rojo, o bien empleando solo uno de estos dos (SOLER, 1988: 243).

En cuanto a la realización del trazado del dibujo, el ceramista podía hacerlo mediante la utilización de estarcidos. Estos se confeccionaban con un cartón o papel algo rígido donde se diseñaba el dibujo, que posteriormente se recortaba y se punzaba todo el contorno del diseño, con una aguja. Puesto este, sobre la superficie del tablero, se transfería el dibujo al pasar por encima algún colorante (generalmente se utilizaba carboncillo). Los estarcidos servían como guía y permitían la producción de idénticas copias de un mismo motivo. 
A pesar de la facilidad que presentaba para la ejecución de la decoración la utilización de estarcidos, no todos optaban por esta técnica y eran muchos los socarrats pintados a mano alzada, con la consiguiente dificultad de tener que acoplar el dibujo al formato del soporte, cosa que en ocasiones no se conseguía, teniendo que omitir una parte de este o reduciéndolo.

Una vez repasado el perfilado del motivo, con la utilización de pigmento negro o rojo, se rellenaba este utilizando única y exclusivamente estos dos colores sobre el fondo blanco. La pieza terminada, adquiría un aspecto final tosco, áspero y sin vidriado.

Tan importante como la realización de la pieza, era el secado, que debía realizase de forma natural, teniendo especial cuidado para que la plancha no se curvase por un exceso o des uniforme secado. Para ello se acostumbraba a colocar peso en las esquinas, evitando de esta manera, que estas se deformasen. Esta operación solía llevar varios días, y era de vital importancia que se realizará correctamente pues, cualquier residuo de humedad en el interior de la pieza, podía provocar la explosión de la misma al hornearla.

Y una vez, ahora sí, completamente seca se la sometía a una sola cocción. La cocción de las piezas se realizaba en hornos de origen islámico llamados hornos morunos. Para la construcción de estos hornos se utilizaba ladrillo, piedras y barro, siendo por lo general de forma circular. Estaban formados por dos partes, una de ellas enterrada en donde se originaba el fuego, y la otra, correspondiente a la cámara de cocción, que contaba con una bóveda y varias aberturas que permitían al alfarero tener un buen control del fuego, bien tapándolas o destapándolas hasta conseguir la temperatura deseada en cada momento de la cocción.

\subsection{Principales motivos iconográficos representados en ellos y su simbología.}

Al igual que en el resto de la cerámica de Manises y Paterna, también en los socarrats encontramos decoraciones geométricas como tema principal, la más común es la que cuadricula todo el socarrat. La utilización de los motivos decorativos geométricos es muy común en los fondos de este tipo de piezas. Entre ellos encontramos pequeñas espirales y círculos simples o dobles. También encontramos motivos derivados de la cenefa que aparece en la tela de un sudario bizantino.

En cuanto a los temas vegetales, al igual que los geométricos, los encontramos tanto como tema principal del socarrat como de acompañamiento o de relleno de fondo.

La palmeta es representada en múltiples variantes. Igualmente las hojas, grandes o pequeñas, anchas o estrechas, y gran variedad de flores, con cinco pétalos las más usuales. Tanto en el interior de las hojas como en el de las flores, sobre todo en las de mayor tamaño, otros motivos sirven de relleno de estas.

Los motivos zoomorfos son muy variados, pudiendo encontrar peces, que cuando aparecen en una composición de tres, tienen un ojo en común. 
A este tipo de socarrats se le ha dado dos interpretaciones. La primera sería la de que representaban el movimiento, y la segunda, referida a una interpretación bajo el punto de vista cristiano, en la que el triangulo que forma el ojo central simbolizaría el ojo Eterno, y los tres peces harían referencia a las tres personas de la Santísima Trinidad (GONZÁLEZ, 1944: 425).

Los animales terrestre son también aquí, al igual que en la cerámica vidriada, muy usuales, y entre ellos encontramos mamíferos como el ciervo, el toro, el gato, el conejo, el jabalí y el león. Las aves más habituales en los socarrats son el gallo y el águila, pero también podemos ver otras que en ocasiones son difíciles de identificar.

En todos los socarrats con figuras de mujer, esta lleva un traje de tela listada, sus siluetas se ajustan a la moda de la época, en la que las mangas eran vaporosas y se ceñían a la altura de la muñeca. Las faldas no solían representarse con cola. En ocasiones las encontramos con medallones. Sus cabezas pueden estar cubiertas con sombreretes o con una red, que encierra el cabello, cayendo sobre la espalda.

La figura masculina, la podemos encontrar en socarrats en los que aparece un rey. En otros se trata de un caballero, que aprisiona a seres fantásticos en los que creían las gentes en época medieval. Algunos de estos luchadores llevan un "barret" en la cabeza y una espada en la mano izquierda, mientras que con la otra sostienen el escudo defensivo. También podemos ver jinetes con su escudo y su lanza.

El tráfico de esclavos también queda reflejado en los socarrats, en los que nos muestran embarcaciones cargadas de esclavos de color, a pesar de estar prohibida esta pràctica.

Los socarrats con ángeles nos ofrecen dos variantes: en la primera, en que son representados sin brazos, pero con alas, y una segunda en la que aparecen sin alas con los brazos cubiertos por pavorosas y largas mangas. Las vestimentas de los ángeles son semejantes a las de las mujeres de otros socarrats, incluso en las telas de sus vestidos que también son rayadas. Lo cierto es que lo que hace que se considere que se trata de ángeles, es el hecho de llevar nimbada la cabeza, símbolo de divinidad.

Otras piezas aparecen decoradas con escudo con figuras accesorias, que nos muestran dos figuras humanas, normalmente masculinas aunque se ha encontrado uno con una figura de mujer, que sostienen el escudo, coronado por una hoja, piña o flor de lis. En algunos aparece en el centro del escudo un blasón, el de los Luna. En muchos de los socarrat se pueden encontrar escudos heráldicos. Otro motivo son los castillos, aunque realmente no se trata sino de una torre de estos.

\subsection{Estudio comparativo de la iconografía}

El análisis de los motivos iconográficos lo realizaré a partir de piezas de la cerámica vidriada, esa esta, de la época verde-morada o azul, y la de reflejo dorado, en cuya decoración encontramos motivos animalísticos, heráldicos, figuras y escenas caballerescas, con otra de piezas de socarrats, todas ellas producidas durante estos siglos, con el objetivo de ver cuáles 
han sido los principales motivos transferidos, y de cómo se ha realizado esa transferencia desde el soporte de vajilla al de las piezas conocidas como socarrats, determinando las variaciones que encontramos de un mismo motivo para adaptarse a ellos.

Llegado a este punto, se han elegido cinco piezas, al azar, tanto de la cerámica dorada, como de la verde-manganeso, intentando encontrar su equivalente en la obra realizada con la técnica del socarrat, y de este modo poder realizar una comparación más aproximada de esa transferencia de motivos, de un tipo de soporte al otro.

En las figuras 1 y 2 aparece la figura del león rampante, siempre representado de perfil, correspondiendo la figura 1 a un plato de loza dorada de Manises del siglo XVI. El león esta dibujado en el centro del plato, a lo largo de su diámetro, quedando completamente en vertical, y adaptándose a la horma de este. Para rellenar el triangulo formado entre las patas delanteras, la panza y las patas traseras, se traza una rama de tres hojas dispuestas formando un triangulo, ocupando la cola la parte trasera del león.

La figura 2 en la que el león rampante del socarrat de Paterna del primer tercio del siglo XV, la forma que tiene para adaptarse al formato de este, que es casi cuadrado $(31 \times 35 \mathrm{~cm})$ y seguir conservando la idea del rampante, es colocarlo en posición horizontal, con una de sus patas delanteras en la horizontal inferior y la otra apuntando a la vertical. La pata trasera izquierda rellena el ángulo más cercano a esta, formando una diagonal con la cabeza. La cola alta sobre la espalda roza la paralela superior, todos los huecos restantes son ocupados con motivos de relleno.

La heráldica la hallamos en piezas de formatos muy variados. Como vemos en la figura 3 , dentro de la cerámica vidriada la podemos encontrar incorporada en la decoración de platos, constituyendo el motivo central de estos, en este caso el escudo de Boil, con las armas cuarteadas de León y Castilla, cubriéndose el resto de la superficie de la pieza con lirios contrapeados y ataurique dispuestos en una composición de lazo (MARTINEZ, 1991: 161). Cuando el alfarero transfiere esta iconografía al soporte de las placas de techo, lo hace de manera que esta ocupa toda la superficie cerámica. Los bordes exteriores del escudo que aparece en el plato y los ef de la placa de techo, quedan remarcando el interior del escudo.

Otra variante en los escudos es la del plato de la figura 5, realizado con motivo del enlace matrimonial de la hija del señor de Manises con el rey de Aragón, en donde se trazan los dos escudos, dibujados de forma simétrica, rellenando los espacios sobrantes con temas geométricos. Al pasar al soporte del socarrat el escudo (figura 6), el artista lo coloca centrado en la plancha, quedando el resto de la placa cubierta con motivos secundarios, que son una variante de la palmeta copta o bizantina. El escudo esta partido de arriba abajo en dos cuarteles, en cuyo interior, en el primero, se presenta el bastión de Aragón y en el segundo el de la casa Luna. 
El plato de Paterna (figura 7) realizado en verde y manganeso, nos muestra un torreón almenado como motivo central, con puerta de medio punto y tres ventanas que parecen góticas. En la parte inferior de la torre vemos lo que posiblemente quiere simular un muro, en cuyo interior hay tres palmetas coptas. En ambos lados del torreón se pintan cuatro piñas simétricas, dos en la parte derecha y dos en la izquierda.

La transferencia de este motivo a la placa de socarrat se realiza de manera muy similar, centrando el torreón, que también aparece aislado, en el que igualmente se representan cuatro almenas en su parte superior y en la inferior otro tipo de esquema para el posible muro. En este caso (figura 8) solo se sitúan dos ventanas, a cuyos pies se reserva un rectángulo en blanco, que abarca la misma anchura que ambas ventanas juntas, a modo de balcón. Los huecos restantes, en ambos lados, son rellenados mediante palmetas bizantinas con extensiones prolongadas y un disco.

La figura 9 con escena caballeresca de la cerámica verde y manganeso de Paterna, es obrada utilizando como soporte un plato de loza. La escena que en él se presenta está compuesta por un noble caballero con birrete en la cabeza, y su caballo tordo, galopando al encuentro de su contrincante. El jinete empuña la lanza con la mano derecha, mientras que la izquierda carga con el escudo. Ambas figuras se muestran dibujadas con gran detalle y cubren la mayor parte de la superficie del plato, completándose el resto con motivos vegetales como la hoja de trébol y ramas en espiral de las que brotas diferentes modelos de hojas.

Al pasar al socarrat de Paterna del siglo XV (figura 10), apreciamos una variante significativa en cuanto a dirección, ya en él el jinete con escudete, lanza y caballo huye, al parecer, del ataque de otros agresores (GONZÁLEZ, 1944: 449). Podemos interpretar que la huida se produce a gran velocidad por la disposición de las extremidades del caballo, completamente estiradas, que parecen no rozar el suelo. Resulta sorprendente, tratándose de un socarrat, el realismo con que se dibujan las patas y los cascos del caballo. En este caso el caballero no lleva birrete sino sombreo, y a diferencia de la escena del plato de loza, en este último caso la silueta que dibujada deja muchos espacios sin cubrir, que son subsanados mediante la incorporación de cinco grandes palmetas coptas o bizantinas con variantes entre ellas, y otras más pequeñas realizadas con un solo trazo. El resto del socarrat esta colmado con pequeños elementos sin ningún significado, cuya única función es la de relleno.

Como podemos ver a través de las piezas estudiadas, no parece existir diferenciaciones significativas en cuanto a la iconografía de la representación de los mismos elementos, salvo en los que se refiere a los de relleno de fondo y al hecho de que en los socarrats, por lo general, el trazo es más libre, primando la espontaneidad. 


\section{Conclusiones}

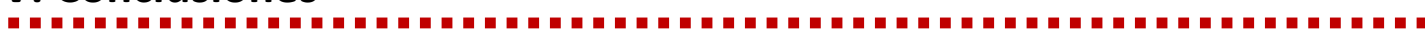

Como resultado de la revisión historiográfica e iconográfica, sobre distintos aspectos de la cerámica de Manises y Paterna, llevada a cabo a lo largo de este trabajo, podemos concluir varios puntos: en primer lugar que, en los principales motivos decorativos, que encontramos en sus respectivas piezas, no cabe hacer una diferenciación en cuanto a si fueron ejecutados en Manises o en Paterna, ya que en ambas poblaciones estos se repiten, y las diferencias que podemos descubrir se basan más en la diacronía de su iconografía que en la procedencia de las obras. Como única salvedad mencionar que, la cerámica verde y manganeso predomina en los alfares de Paterna y la de reflejo dorado en los de Manises, no significando esto la exclusión de ninguna de las dos en la otra población.

Por otro lado, nos preguntábamos qué son los socarrats, técnica utilizada para su elaboración, y los motivos que hallamos en ellos. Solo sintetizar diciendo que son placas ornamentales que han formado parte de la estructura arquitectónica de algunos palacios, casas e iglesias. El resto de interrogantes considero que quedan suficientemente contestados, al menos en esta primera aproximación a los socarrats, a lo largo del presente trabajo.

Vale la pena insistir en que, a lo largo del estudio comparativo de la transferencia de motivos iconográficos, entre los distintos tipos de cerámicas a las placas de los socarrats, encontramos que son, en su gran mayoría, replicas de la loza, sobre todo de piezas de la cerámica en verde y manganeso, motivado posiblemente por el hecho de que ambas se dan, principalmente, durante los siglos XIV - XVI en Paterna.

En razón de lo anteriormente mencionado, podemos afirmar la hipótesis inicial de la continuidad de los mismos motivos decorativos a lo largo de los siglos XIV al XVI, con el rediseño de estos, para adaptarse al formato de la placa, cuyas proporciones más comunes son $32 \times 24 \mathrm{~cm}$. Pero si repasamos las dimensiones que tienen los tableros conservados, nos damos cuenta de que existe una gran variedad.

No puedo permitirme cerrar estas conclusiones sin señalar que el hecho de no encontrar socarrats en otras zonas, exceptuando los que se localizan en la comunidad valenciana, no significa que no se dieran, incluso que los que en Paterna y Manises se producían, se exportaran. Lo que sería motivo de un nuevo estudio. 
VII. Bibliografía

ARANEGI GASCÓ, C. (1987): Historia de la Cerámica Valenciana. Tomo II. Valencia. Vicent García Editores S.A

ARIAS, C. BERTI, G. (1973): Análisis con fluorescencia. IV Congreso Internacional de la Cerámica,pp.127-134

BERNAT VISTARINI, A y J. T CULL (1999): Enciclopedia Akal de Emblemas españoles ilustrados. Madrid. Ediciones. Akal, S.A

BIRKS, T. (1995): Guía completa del ceramista. Barcelona. Blume Naturart, S.A Bestiario Medieval (1986). Madrid. Ediciones Siruela.

COLL CONESA, J (1996): Recientes intervenciones de restauración sobre recubrimientos cerámicos exteriores de arquitectura en España. (pp 453-466). En el acta del XI Congreso de Conservación y Restauración de Bienes Culturales. Castellón.

COLL CONESA, J (2009): "La cerámica de los siglos XVI y XVII (15001700)». Historia de la Cerámica Valenciana. AVEC, Asociación Valenciana de Cerámica. Consultado el 15 del 12 del 2013

CURSA RAMOS, J (1974): Revestimientos. Barcelona. CEAC.

DE CARDENAS; VICENT, V (2002): Diccionario Heráldico: Términos, piezas y figuras usadas en la ciencia del blasón. Madrid. Editorial Hidalguía.

DE CARDENAS; VICENT, V (1985): Repertorio Blasones Comunidad Hispánica. Apéndice 1. Madrid. Editorial Consejo Superior de investigaciones científicas. EIROA RODRÍGUEZ, J. A (2006): Antigüedades Medievales. Madrid. Editorial Martí Almagro-Gorbea.

ESSAYS, N (1996): Glasgow Emblem Studies, vol I. Emblems and Art History. Scotland. Edited by Alison Adams.

FERNÁNDEZ CHITI, J (1984): Diccionario de la cerámica. Ed. Condorhuari.

FERNANDEZ CHITI, J (1985): Diccionario de cerámica (T.3): letras N hasta la Z. Buenos Aires. Editorial Paradox.

GONZALEZ MARTI, M (1944): Cerámica del Levante español: siglos medievales. Volumen III: azulejos y retablos "socarrats". Valencia. Editorial Labor.

JUNIO, A (2013): Emblemas. Zaragoza. Edita Libros Pórtico.

KAPPELER, C (1980): Monstres, démons et merveilles à la fin du Moyen Age. Paris. Éditions Payot.

LEACH, B (1981): El manual del ceramista. Barcelona. Blume.

MARTINEZ CALVIO, B (1991): Cerámica Hispanomusulmana andalusí y mudéjar. Madrid. Editorial El visor.

MIDGLEY, B (1981): Guía completa de escultura, modelado y cerámica, técnicas y materiales. Madrid. Editorial Hermann Blume. 
MORLEY-FLETCHER, H (1985): Técnicas de los grandes maestros de la alfarería y cerámica. Madrid. Editorial Blume.

PITARCH ROIG, A.M (2002): Reflexiones sobre la utilización de la cerámica arquitectónica en exteriores. Ponencia no 77, Congreso Qualicer . Castellón PINEDO, C y VIZAINO, E (1988): La cerámica de Manises en la historia. León. Everest.

PORCAR, J.L (1987): Manual-guía técnica de los revestimientos cerámicos.

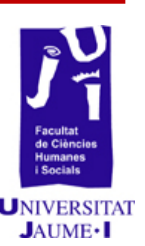
Castellón. Publicación Instituto de tecnología cerámica. Diputación de Castellón.

RADA, P y HUCEK, M (1992): Le tecniche della cerámica. Praga. Fratelli Melita Editori.

RHODES, D (1987): Hornos para ceramistas. Barcelona. CEAC SOLER FERRER, M P. (1988): Historia de la Cerámica Valenciana. Tomo II. Valencia. Ed. Vicent García Editores S.A

SOLER FERRER, M P. (1989): Historia de la Cerámica Valenciana. Tomo III. Valencia. Vicent García Editores S.A SOLER FERRER, M P y PERÉZ CAMPS, J. (1992): Historia de la Cerámica Valenciana. Tomo IV. Valencia. Vicent García Editores S.A VILLANUEVA MORTE, C. (2006): Estudio de la producción y comercialización de la cerámica bajomedieval entre los reinos de Aragón y Valencia. Revista Histórica Medieval, no 14, pp. 249-287. Universidad de Zaragoza.

VITTEL, C (1986): Cerámica (pastas y vidriados). Madrid. Editorial Paraninfo, S.A

\section{MATERIAL GRÀFIC}

Figura 1

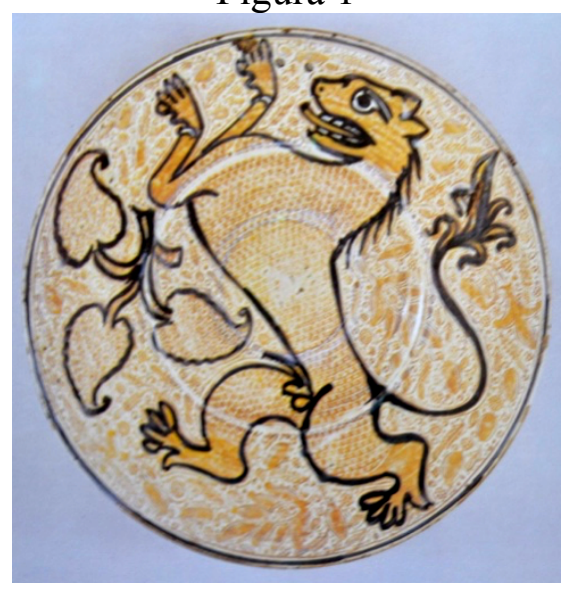

Fuente: Historia de la Cerámica Valenciana. Tomo II. SOLER, M. (1988:164)

Instituto Valencia de Don Juan. Madrid. 
Figura 2
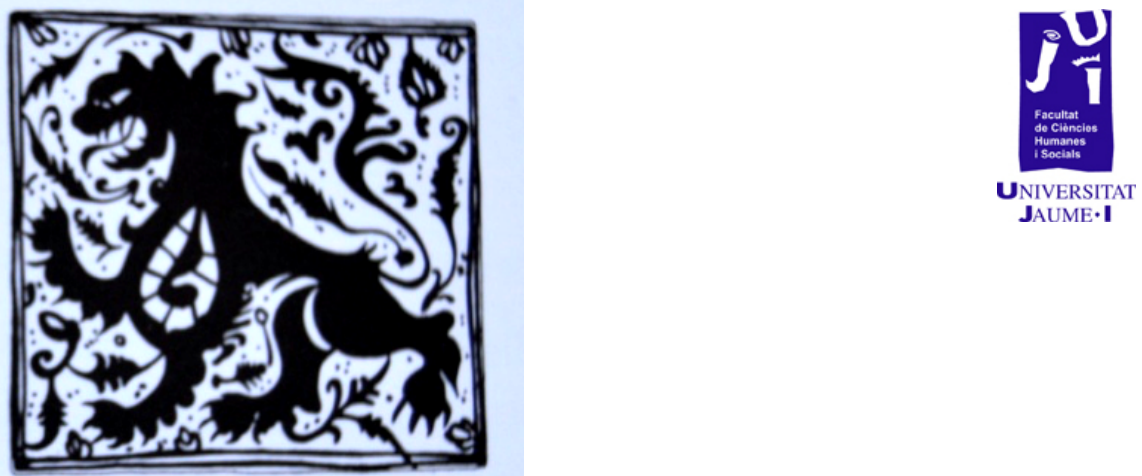

Fuente: Cerámica Hispanomusulmana. MARTÍNEZ, B. (1991: 217)

Figura 3

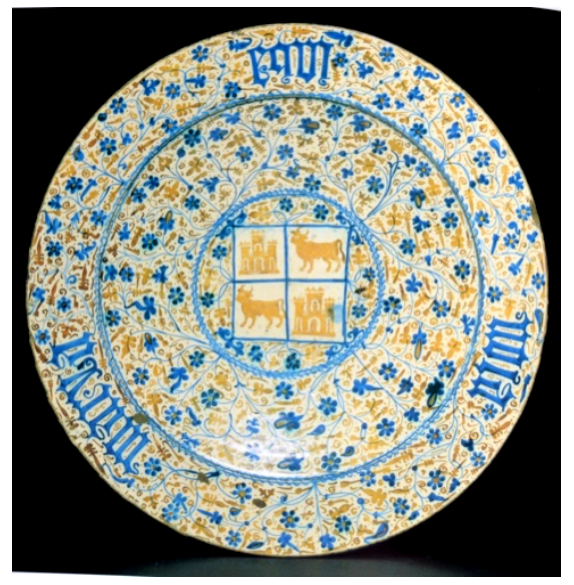

Fuente: Cerámica Hispanomusulmana. MARTINEZ, B. (1991:160)

Hispanic Society 
Figura 4

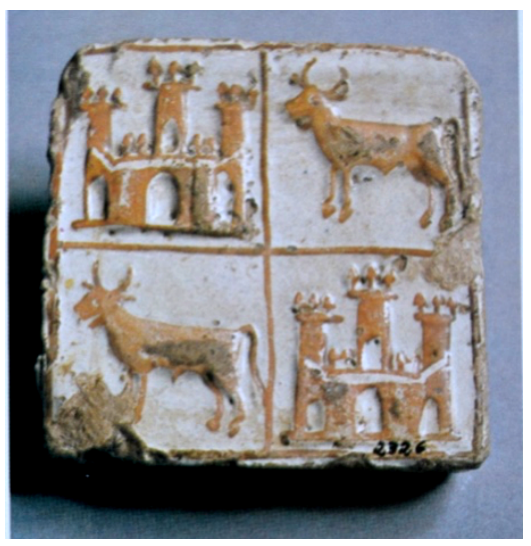

Fuente: Historia de la Cerámica Valenciana. Tomo II. SOLER, M. (1988:205)

Museo Nacional de Cerámica "González Martí". Valencia

Figura 5

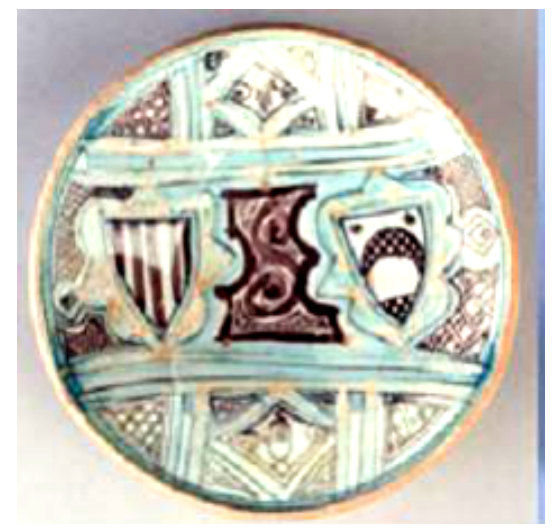

Fuente: La cerámica de Manises en la Historia. PINEDO, C; VICAINO, E. (1988: 34) Museo Nacional de Cerámica "González Martí". Valencia 
Figura 6
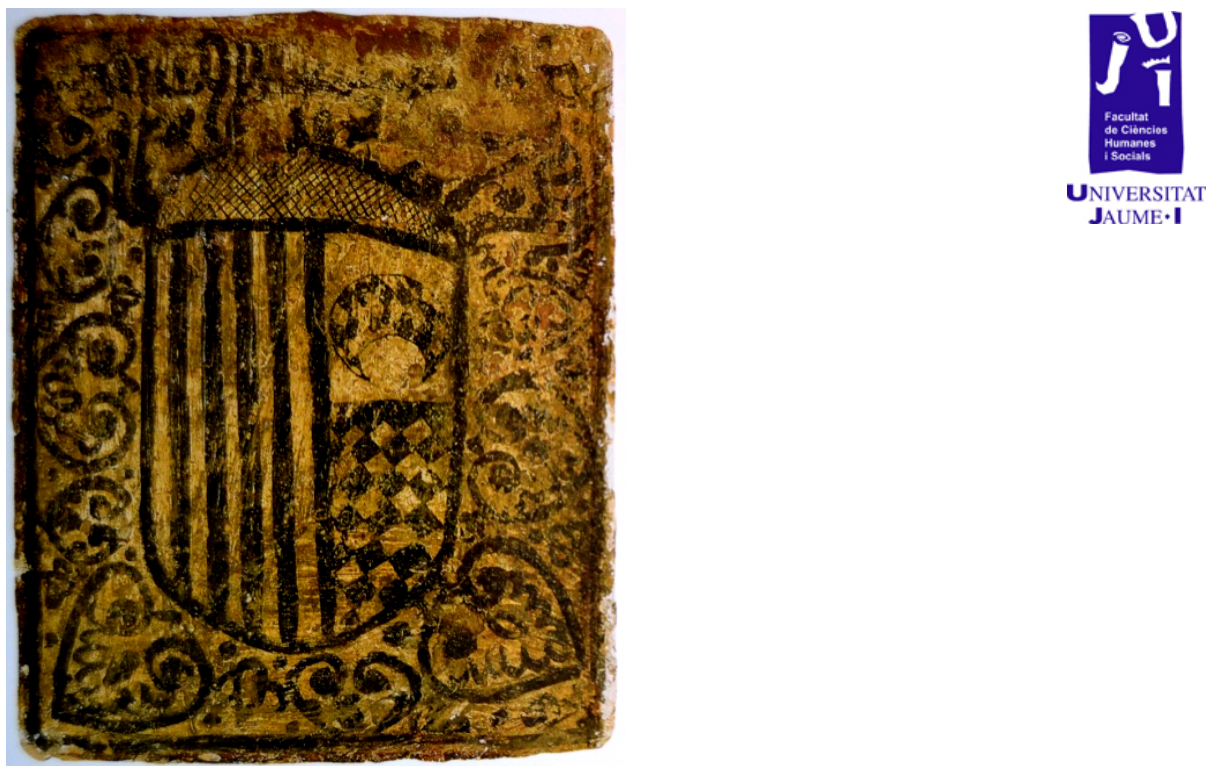

Fuente: Cerámica Hispanomusulmana. MARTÍNEZ, B. (1991:218)

Socarrat de Paterna, primera mitad del s.XV. Tallero de 48 × $35 \mathrm{~cm}$, decorado con el escudo de Aragón y de Casa Luna. Museo Nacional de Cerámica, Valencia.

Figura 7

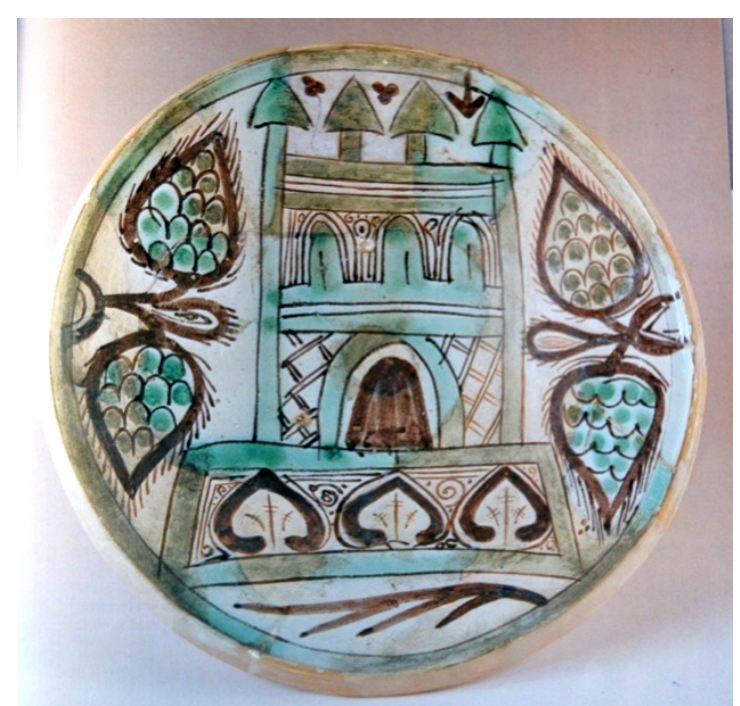

Fuente: Historia de la Cerámica Valenciana. Tomo II. SOLER, M. (1988:93)

Museo Nacional de Cerámica "González Marti”". Valencia 
Figura 8

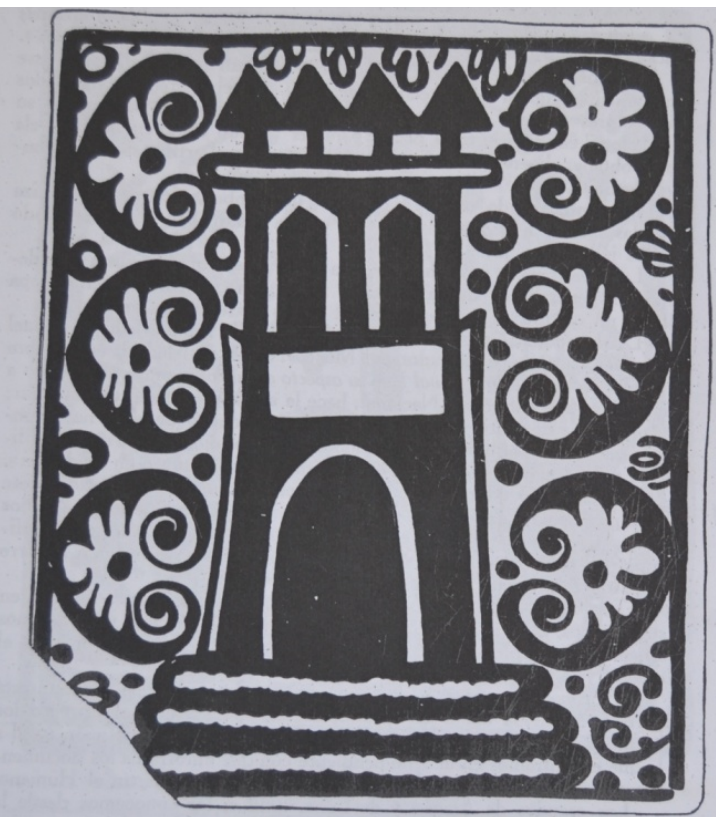

Fuente: Cerámica del Levante español: siglos medievales. Volumen III: azulejos y retablos "socarrats". (GONZÁLEZ, 1944: 460).
Figura 9

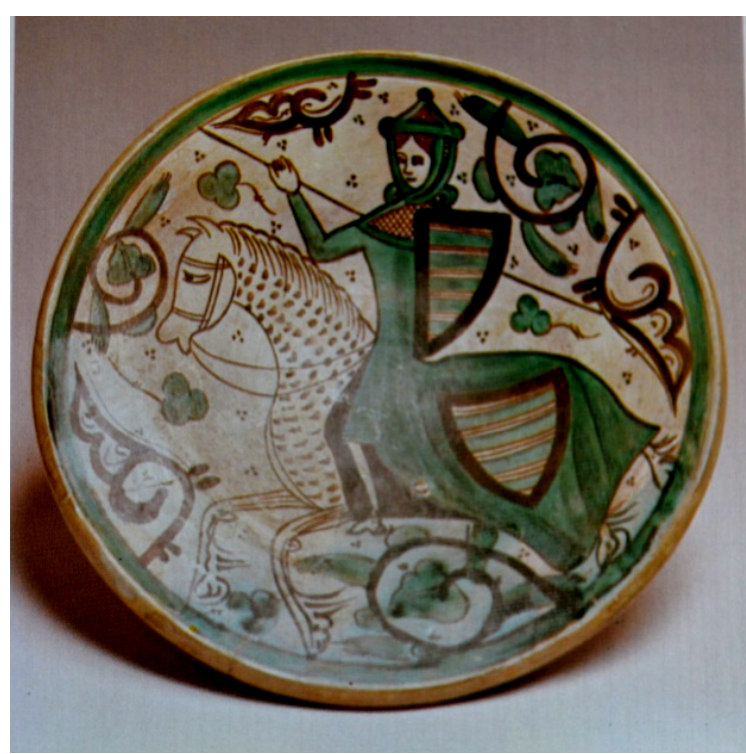

Fuente: La cerámica de Manises en la Historia. PINEDO, C; VICAINO, E. (1988: 25) Museo Nacional de Cerámica "González Martí”. Valencia 
Figura 10
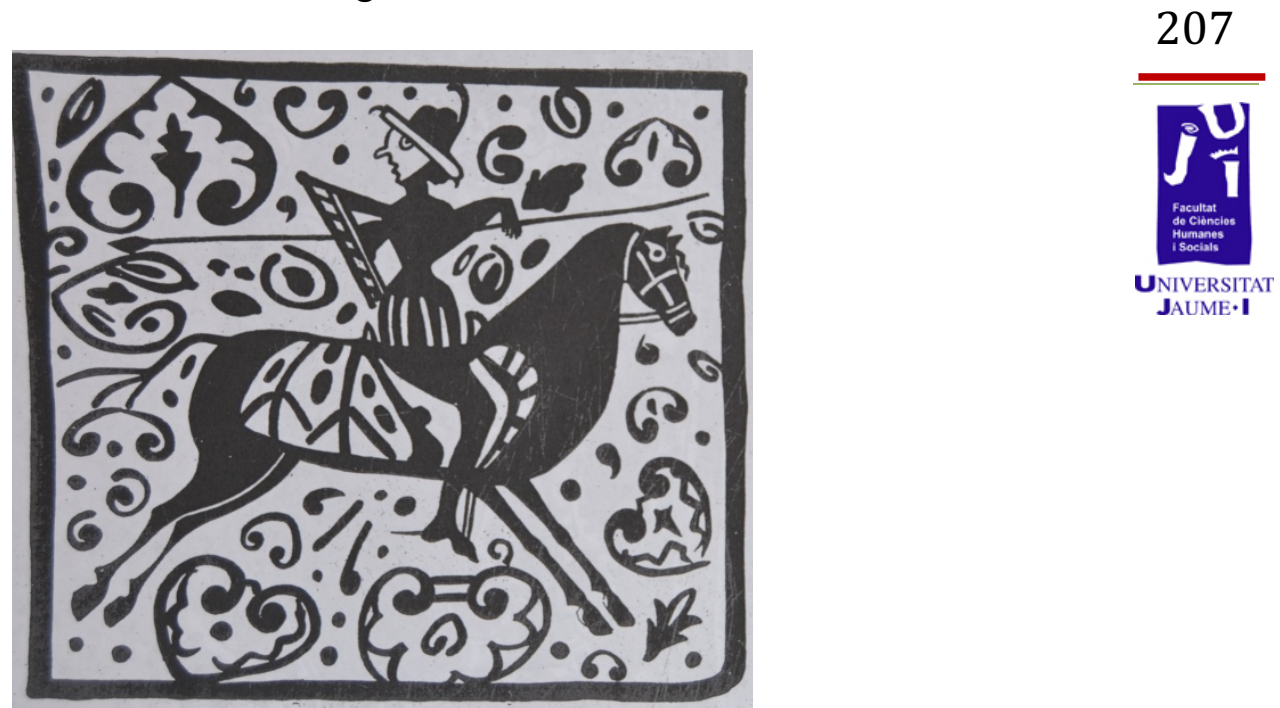

Fuente: Cerámica del Levante español: siglos medievales. Volumen III: azulejos y retablos "socarrats". (GONZÁLEZ, 1944: 460). Museo Nacional de Cerámica "González Martí". Valencia 